\title{
Retroflexion and prevention of right-sided colon cancer following colonoscopy: How I approach it
}

\author{
Douglas K Rex ${ }^{1} \mathrm{MD}$, MACG
}

1. Indiana University School of Medicine

Division of Gastroenterology/Hepatology

Indianapolis, Indiana

Address correspondence to:

Douglas K Rex MD

Indiana University Hospital 4100

550 N University Boulevard

Indianapolis, Indiana 46202

drex@iu.edu

This is the author's manuscript of the article published in final edited form as:

Rex, D. K. (2016). How I Approach Retroflexion and Prevention of Right-Sided Colon Cancer Following Colonoscopy. The American Journal of Gastroenterology, 111(1), 9-11. https://doi.org/10.1038/ajg.2015.385 


\section{The Big Picture}

Colonoscopy is less effective in preventing right sided compared to left sided colon cancer ${ }^{1,2}$. The risk of colon cancer after colonoscopy is a function of 3 factors (Table 1). First, a higher prevalence of neoplasia provides greater opportunity to miss neoplasia during colonoscopy. The prevalence of neoplasia can be predicted prior to colonoscopy by the indication and patient demographics (Table 1). Detection of lesions during colonoscopy, especially if multiple, further informs the colonoscopist of an increased risk of missed lesions. I respond to increased risk of missing by performing at least two meticulous right colon examinations.

Second, the subtlety of lesions (low profile, pale color, hard to access location) affects the risk of missing. Serrated lesions and conventional adenomas with flat and depressed morphology are all distributed toward the right colon ${ }^{3}$. Subtlety is overcome by excellent bowel preparation, colonoscopist knowledge of disease spectrum, colonoscopist recognition skills, and high definition imaging. Adjunctive tools including chromoendoscopy and mucosal exposure devices are used by some endoscopists to increase detection ${ }^{4}$.

Third, and most important, is endoscopist skill, as measured by the adenoma detection rate (ADR) ${ }^{5}$. ADR is enhanced by ADR measurement and reporting and education in examination technique and lesion recognition. The same tools that improve exposure and visualization of subtle lesions can improve ADR.

These 3 factors interact to determine outcome. Extreme subtlety of a lesion or hard to access location may foil the efforts of the most skilled colonoscopist. Colonoscopy is not perfect and 
the expert seeks to minimize but cannot currently eliminate the risk of interval cancer. At the other extreme, high disease prevalence and an unskilled colonoscopist are a recipe for disaster ${ }^{6}$.

General strategy for prevention of right colon cancer at colonoscopy Following split-dose or same-day preparation, the endoscopist first performs a meticulous examination from the appendiceal orifice to the hepatic flexure. If the pre-procedure prediction of disease prevalence is high or if the first examination reveals lesions, a second examination is performed (Figure 1). The colonoscope is re-inserted to the cecum, and the cecum is always reexamined in the forward view. This repeat examination of the cecum in the forward view is critical, since the cecum is incompletely seen in retroflexion, and missing in the cecum is common during colonoscopy.

After cecal re-inspection, a decision is made to repeat the ascending colon examination in the forward view or in retroflexion. Surprisingly, this decision is not important for patient outcomes. Specifically, two randomized controlled trials found that the miss rate of the first examination is not affected by whether the second examination was performed in retroflexion vs the forward view $^{7,8}$. The colonoscopist must recognize that the value to the patient comes from performance of the second examination, and accrues regardless of whether the second examination is forward or retro viewing.

This assertion raises the question of whether to do right colon retroflexion at all. I prefer the second examination in retroflexion in many cases and recommend that all colonoscopists learn proximal colon retroflexion because it is safe and is an essential tool in some polyp resections ${ }^{9}$. 
I usually decide to perform a second examination of the right colon in retroflexion vs forward view based on factors such as large luminal diameter, straight (not angulated) right colon anatomy, and a straight insertion tube (60-90 $\mathrm{cm}$ of instrument in the patient with the tip in the cecum), all of which make retroflexion easier to perform.

Technique of right colon retroflexion

With the colonoscope tip in or near the cecum, turn the dials to the maximum up and maximum left directions. The bending section will now be hairpinned in the up-down deflection plane (try this outside the patient to understand bending section dynamics). Rotate the colonoscope insertion tube counter-clockwise to enter retroflexion. If the cecum is large the ileocecal valve may be visible, but at times the instrument tip will be distal to the valve. A photograph is taken, and inspection is conducted as the instrument is withdrawn toward the hepatic flexure, where a second photograph is taken. Retroflexion is reversed by releasing the up-down and right-left controls and simultaneously withdrawing the insertion tube, so that the bending section exerts minimal pressure on the colon wall as it unwinds. The colonoscope is then advanced far enough to be certain that resumption of forward viewing overlaps with the first forward examination of the right colon.

\section{Documentation}

Detailed documentation is essential to quality measurements of cecal intubation rates and is important to the defense of malpractice actions alleging negligent examination of the right colon. Forward viewing photographs of the appendiceal orifice and ileocecal valve (and terminal ileum 
if entered) prove that full cecal intubation occurred. Additional photographs of the right colon in the forward view and particularly from a second examination in retroflexion (Figure 2) add to the evidence of adequate preparation and performance of a state-of the art examination.

Summary

Improving protection against right sided colon cancer is a major goal for modern colonoscopy. Two or more meticulous right colon examinations are advocated as a routine measure when the pre-colonoscopy estimate of neoplasia prevalence is high or when the actual prevalence of disease encountered in the first examination is substantial. Whether the second examination is performed in the forward or retro view is not critical to optimal detection, but the ability to retroflex in the proximal colon should be practiced because of its essential role in some polyp resections. 
Table 1. Factors conspiring to cause interval (post colonoscopy) cancers

\begin{tabular}{|c|c|c|}
\hline Factor & Predictors of factor & $\begin{array}{l}\text { Solutions to improved } \\
\text { detection }\end{array}$ \\
\hline High prevalence of neoplasia & $\begin{array}{l}\text { 1. Pre-procedure: Older } \\
\text { age; indication of } \\
\text { bleeding, especially } \\
\text { positive FOBT or FIT } \\
\text { 2. Intraprocedure: First } \\
\text { exam detects } \\
\text { neoplasia, especially } \\
\text { large, multiple lesions }\end{array}$ & $\begin{array}{l}\text { Examine segment two or } \\
\text { more times }\end{array}$ \\
\hline $\begin{array}{l}\text { Subtle endoscopic appearance } \\
\text { or hidden location }\end{array}$ & $\begin{array}{l}\text { 1. Subtle lesions: right } \\
\text { colon location } \\
\text { 2. Hidden: proximal } \\
\text { sides of folds; flexures }\end{array}$ & $\begin{array}{l}\text { Split-dose or same day bowel } \\
\text { preparation; educated } \\
\text { endoscopist; double } \\
\text { examination; } \\
\text { chromoendoscopy; mucosal } \\
\text { exposure tools }\end{array}$ \\
\hline Poor colonoscopy skills & 1. Low ADR & $\begin{array}{l}\text { Education on technique and } \\
\text { lesion recognition, ADR } \\
\text { measurement and reporting, } \\
\text { endoscopic tools for detection } \\
\text { of subtle and hidden lesions } \\
\text { (as above) }\end{array}$ \\
\hline
\end{tabular}

ADR: adenoma detection rate

FOBT: fecal occult blood test

FIT: fecal immunochemical test 
Figure 1.

Forward viewing meticulous right colon examination

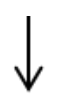

High pre-colonoscopy probability of neoplasia

or

Lesions detected in first exam

$\downarrow$

Reinsert to appendiceal orifice and perform second exam of cecum in the forward view

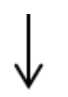

Proceed to second exam of ascending colon

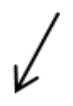

Lumen large

Right colon straight

Insertion tube straight

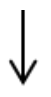

Second exam of ascending colon in retroflexion

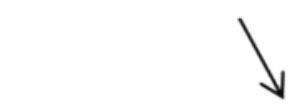

Lumen narrow

Right colon angulated

Loop or bend in insertion tube

$\downarrow$

Second exam of ascending colon in forward view 
Figure legends

Figure1. Author's approach to second right colon examinations during colonoscopy

Figure 2. Examples of high quality right colon documentation
A. Appendiceal orifice
B. Terminal ileum
C. Ileocecal valve
D. Forward view of ascending colon from near hepatic flexure
E. Proximal ascending colon retroflexed view
F. Retroflexion from near the hepatic flexure 


\section{References:}

1. Baxter NN, Warren JL, Barrett MJ, Stukel TA, Doria-Rose VP. Association between colonoscopy and colorectal cancer mortality in a US cohort according to site of cancer and colonoscopist specialty. J Clin Oncol 2012;30:2664-9.

2. Brenner H, Hoffmeister M, Arndt V, Stegmaier C, Altenhofen L, Haug U. Protection from rightand left-sided colorectal neoplasms after colonoscopy: population-based study. J Natl Cancer Inst 2010;102:89-95.

3. Rex DK. Preventing colorectal cancer and cancer mortality with colonoscopy: what we know and what we don't know. Endoscopy 2010;42:320-3.

4. Chaptini L, Laine L. Can I improve my adenoma detection rate? J Clin Gastroenterol 2015;49:27081.

5. Rex DK, Schoenfeld PS, Cohen J, et al. Quality Indicators for Colonoscopy. Am J Gastroenterol 2015;110:72-90.

6. Chiu SY, Chuang SL, Chen SL, et al. Faecal haemoglobin concentration influences risk prediction of interval cancers resulting from inadequate colonoscopy quality: analysis of the Taiwanese Nationwide Colorectal Cancer Screening Program. Gut 2015.

7. Harrison M, Singh N, Rex DK. Impact of proximal colon retroflexion on adenoma miss rates. Am J Gastroenterol 2004;99:519-22.

8. Kushnir VM, Oh YS, Hollander T, et al. Impact of retroflexion vs. second forward view examination of the right colon on adenoma detection: a comparison study. Am J Gastroenterol 2015;110:415-22.

9. Rex DK, Khashab M. Colonoscopic polypectomy in retroflexion. Gastrointest Endosc 2006;63:144-8. 